\title{
Research and Application of Information Technology in Construction Enterprise
}

\author{
Weidong Liu \\ Applied Technology College of Dalian Ocean University, Dalian, Liaoning, China
}

\section{Keywords: Application, Information Technology, Construction Enterprise}

\begin{abstract}
At present, our time is an era of information and this era is a significant feature of information technology in a wide range of industries. The development and improvement of information technology has made great contributions to Chinese economic take-off, but it also brought new development opportunities for the development of traditional industries. In China, most of the construction enterprises use the traditional method of construction management, and with the economic globalization and the fierce competition in the market, the traditional management model has been unable to adapt to the needs of the development of the new situation, such as the transmission of information caused by the slow management In the lag of communication and so on. In this severe situation, many construction enterprises in order to improve their competitiveness, in order to gain a firm foothold in the market, began to focus on the use of information technology. Information technology in the construction industry is mainly used in the production process of information technology and management of information technology and we mainly study the application of information technology in construction enterprises. This paper mainly starts from the particularity of the management of construction enterprises, and discusses the measures to strengthen the information management of construction enterprises through the analysis of the application status and problems of information technology in the construction of construction enterprises.
\end{abstract}

\section{Introduction}

In recent years, the computer as the core of information technology has been rapid development, the resulting wave of global information revolution swept, and unstoppable. The use of information technology to achieve enterprise information has become an indispensable part of enterprise development. How to use computer as the core of information technology successfully applied to construction enterprises, improve business efficiency and construction technology level has become a construction project in front of a major issue. We have achieved success in the implementation of enterprise projects by the Third Engineering Bureau of China Construction. This is an example of how to apply information technology to construction enterprises.

We believe that the application of information technology in construction enterprises mainly includes two aspects: First, the use of computer network technology, construction of construction enterprises of the computer network information system, information resources in-depth development and extensive application, and continuously improve the construction Enterprise management level, and then improve the economic efficiency and competitiveness of enterprises; Second, the use of computer as the core of information technology on the construction of traditional construction methods and construction technology for modernization and upgrading.

\section{The Particularity of Construction Enterprise Management}

Construction management enterprises and other industries are more special, more complex management, the specific performance in the following areas: First, the construction of construction enterprises to spend a lot of manpower, material resources and great workload. And to these complex human and material resources for unified management, you need to go through detailed statistics, but also must be strictly planned, which is extremely suffering, by the traditional management means to achieve the construction of a reasonable planning business is also difficulty; the second is the 
management of construction enterprises involved in all aspects, and the management of numerous. Construction enterprises to complete the construction of a building, the need for a special raw material procurement departments, to have a special engineering inspection departments, to have a unified project planning departments, but also the project safety supervision departments, etc., which makes construction enterprise management is very broad; Third, the construction enterprise construction management information is redundant and changeable. Construction needs of the various departments to conduct a reasonable and orderly division of labor and cooperation, the construction of all links are closely linked, all aspects of the exchange of information is also more numerous, construction enterprises will have to achieve the construction of many of these information Unified management is extremely complex.

In addition, the traditional management methods, information preservation is mostly through the paper form, is not conducive to the storage of information, and the slow flow of information, which makes the role of information cannot be achieved in a timely manner, it is easy to cause management mistakes. In addition, with the development of economy, the expansion of construction projects and the difficulty of construction, the information exchange between the various departments of construction enterprises will continue to increase, the transmission of information will be more complicated, the traditional management methods are serious limiting the transmission of information.

\section{The Necessity and Importance of Using Information Technology for Construction Enterprises}

The traditional construction management methods of construction enterprises cannot meet the needs of their market competition. The traditional management of the construction enterprise is mostly communicated by oral communication and written notice. With the increase of the difficulty of the construction project, the increase of the information exchange between the departments and the improvement of the construction quality requirements, the construction management of the construction enterprise becomes more for the complex. Traditional oral expression and other means cannot achieve effective communication between the various departments and it will cause the imbalance between the various departments and so on.

In addition, the management of written notification will lead to the lag between the information transmission between departments, a direct impact on management level and management efficiency. It can be seen that the use of information technology for the construction of construction enterprises is very necessary, it helps to solve the traditional management methods cannot solve the problem.

Construction enterprises in order to improve their competitiveness and maximize the economic benefits, we must use advanced technical means for construction management. First, the information technology can provide a wealth of market information, easy to optimize the construction program; Second, the use of information technology can better achieve the construction of large and medium-sized project control, the right to the construction of information technology, The construction of the complex situation is more easy to control; Third, the use of information technology for construction management can be achieved through the optimization of management to reduce the cost of construction purposes. There are often some unreasonable phenomena in the construction of construction enterprises, and the use of information technology to improve the management level can be found in the construction of the problems, so that we can solve these problems in time to avoid the problem caused by the expansion of the accident and material waste And the other; Fourth, the use of information technology management to help shorten the duration, a statistic shows that the use of information technology for construction management enterprises can shorten the construction period of $20 \%$ or more; Fifth, the use of information technology into construction enterprises Management can improve management and improve resource utilization. 


\section{The Specific Performance of Using Information Technology for Construction Enterprises Management}

At present, OA system in Chinese construction enterprises are also widely used in daily management, many construction companies have basically achieved the construction management of computerization and automation. For example, some construction projects in the construction site will be installed at the construction site such as monitoring equipment, so that the construction of the panorama is fully displayed in front of the computer to observe the construction of the front of the supervisors. Through the monitoring of various corners of the construction phenomenon, managers can promptly find problems in the construction, which eliminates the need for construction personnel to the scene to monitor the trouble, but also to avoid the construction of one-sided monitoring, you can let them from the whole on the grasp of the construction environment to achieve a full range of construction site supervision. In addition, through the camera, you can promptly correct the workers do not regulate the construction behavior, such as wearing helmets, etc., help to protect the safety of workers;

Many construction companies in the attention to the importance of information technology began to set up their own database, changing the traditional management information delivery. In addition the use of the Internet, construction enterprises can be achieved in the online selection of construction materials, online bidding and other public work and you can also use the network to open a network meeting, the project summary on a regular basis. In addition, through the Internet, construction enterprises can keep abreast of the dynamics of other enterprises in the same industry, between each other can achieve a healthy interaction, so that the construction enterprises to learn from other enterprises of outstanding experience and improve their management level. The use of the Internet to establish a variety of application systems, to achieve a full range of construction projects management. It can be timely through the computer, e-mail and other means of information and construction site to communicate with the responsible person to ensure the smooth and safe construction;

The use of information technology to achieve the three-dimensional modeling technology can be more accurate simulation of the construction site, and then to the management staff to show the difficulty of construction and construction of possible problems, so that construction managers can prepare in advance, engineering graphic design and organizational design, making the construction more standardized. The use of advanced information analysis tools, you can accurately grasp the construction of the relevant data, these data can reflect the construction of the project profile, easy to organize the design of the project;

Construction is extremely complex, and the use of statistics and other simulation technology can be people cannot grasp the actual system at once into a more abstract simulation system, so that managers can have a comprehensive understanding of the construction, the construction process can be have an overall grasp. So that we can get the construction of the relevant data, these data can be the basis for our construction, making the construction more reliable and more scientific;

The use of information technology to achieve the virtual reality technology mainly includes artificial intelligence, statistical machine graphics, man-machine interface technology, multimedia industrial construction technology, mechanical technology and its advantage lies in the image vividly broadcast on the computer screen, to the construction staff to bring direct visual stimulation.

\section{Problems in the Application of Information Technology in Construction Technology Management}

First, the management system and software development is relatively backward. In China, the construction of enterprise management to information technology is relatively backward, the information management technology is more monotonous, in the application of the computer, relying too much on its speed advantage and ignore the other construction, not enough to cope with different 
construction management demand and it cannot effectively achieve the sharing of information resources;

Second, the application of information technology is relatively narrow. On the current situation, the use of information technology in construction management is often only in the construction phase of the preparatory stage, and in the construction of the project is rarely applied to information technology. For example, many construction enterprises in the project cost budget and other stages often use information technology to carry out the overall analysis of the project, resulting in the general construction data, after the analysis of these data to complete the project budget management. And in the construction phase of the project, such as the construction schedule and construction safety control of the application of information technology is not much;

Third, the application of information technology to stay in the construction management of computerization and automation, the application depth is not enough. The purpose of using information technology is to improve the economic efficiency of construction enterprises and many construction companies use information technology is only for convenience to facilitate the daily information processing and some effective data records. They did not apply information technology to the entire construction process management. Did not give full play to the advantages of information technology for construction management services;

Fourth, less capital investment, lack of funds is the construction management to achieve an important constraint on information technology. Many construction enterprises are limited by funds, do not want to use advanced technical means to manage, still use the old method of implementation management. Or only willing to use the computer as a basic technical means, making the information processing and processing capacity is not high, cannot really achieve the construction management of information technology; Fifth, the lack of professional information technology management personnel. Information technology requires a higher level of talent, if you do not have the operation of advanced information technology processing capacity, it cannot be better and more managed.

\section{The Specific Measures to Improve the Application of Information Technology in the Construction Management}

First, construction companies must attach great importance to the importance of information technology and we must have a profound understanding of the connotation of information technology. Many construction enterprises in the application of information technology are in the wait-and-see stage, did not realize that information technology in improving the overall significance of the enterprise do not want to put money into the purchase of some advanced equipment. There are some enterprises responsible for the application of information technology misunderstanding, they blindly purchased a lot of advanced technology and equipment, and then established a simple Internet application system, that this has been the management of information technology, information technology understanding too superficial not deep enough, which have a direct impact on the construction of enterprise management information degree. Therefore, as a construction enterprise decision-makers and leaders must change their own ideology, the management of information technology has a comprehensive and full understanding, and ultimately committed to the enterprise information construction;

Second, the information technology should be applied to all aspects of construction management. At present, Chinese construction enterprises in the development of information technology is an important issue is that most of the attention to the early construction of information management. We must focus on changing this limitation, we should put information technology throughout the construction process to all aspects of the process, to make full use of computer and network-based information technology advantages of the construction process to conduct a comprehensive digital management, and ultimately to achieve the entire construction of information management. 


\section{Conclusion}

In summary, it is very important for construction enterprises to implement information management and it is the important weight for enterprise can stand out in the fierce competition in the market. At present, Chinese construction enterprises in the information management still has many problems and we must persevere in the research of information technology to improve Chinese construction enterprises in the information management level.

\section{References}

[1] B. N. Ma, Talking about the Application of Information Technology in Construction Management, J. Technology Monthly, 44 (2010) 146-147

[2] H.X.Zeng, Application of Information Technology in Construction Management, J. Science and Technology Innovation Guide. 18(2005) 55-57.

[3] J.H.Xue, Application of Information Technology in Quality Management of Construction Engineering, J. Fujian Construction Science \& Technology, 32(2012) 189-190.

[4] Y.J.Qi, Research and Application of Information Technology in Construction Enterprise, J. Construction Technology, 4(2007) 38-40. 